\title{
On the mechanisms involved in the tensile strength of a dissimilar Ti6Al4V/316L laser welded assembly
}

\author{
Antoine Mannucci ${ }^{1,2}$, Rodolphe Bolot ${ }^{1, *}$ (D), Iryna Tomashchuk ${ }^{1} \mathbb{D}$, Alexandre Mathieu ${ }^{1}$ (D), Eugèn Cicala ${ }^{1}$, \\ and Sébastien Lafaye ${ }^{2}$ \\ ${ }^{1}$ Laboratoire Interdisciplinaire Carnot de Bourgogne, UMR 6303 CNRS, Université de Bourgogne Franche-Comté, 12 rue \\ de la Fonderie, 71200 Le Creusot, France \\ ${ }^{2}$ Laser Rhône-Alpes, 49-51 Boulevard Paul Langevin, 38600 Fontaine, France
}

Received: 27 April 2021 / Accepted: 28 September 2021

\begin{abstract}
The aim of the present work is to analyze the thermomechanical behavior of dissimilar laser seams by means of FE modeling. The case of a Ti6Al4V/316L assembly with vanadium insert was considered. Effective mechanical properties of the main materials and cords were first estimated from NHT measurements. Modeling of the double pass laser welding process was performed first by considering shrinking of the two weld seams during manufacturing, to get the residual stress state in the welded assembly. Modeling of the tensile test was performed in a second step to study the assembly behavior during loading. In these modeling results, the mesh was the cross-section of the micrograph of the assembly itself. The corresponding stress/strain curve was calculated and results were reported for the residual stress state after manufacturing as well as a stress state close to the Ultimate Tensile Strength.
\end{abstract}

Keywords: laser / dissimilar welding / FEM modeling / residual stresses / tensile load / Ti6Al4V / 316L stainless steel / vanadium insert

\section{Introduction}

Laser welding of titanium alloys to stainless steels is of great interest for chemical, medical and aeronautical industries. However, fusion joining of this dissimilar couple of materials remains challenging because of the formation of brittle intermetallic compounds such as $\mathrm{Fe}_{2} \mathrm{Ti}, \mathrm{FeTi}$ and $\mathrm{Cr}_{7} \mathrm{Fe}_{17} \mathrm{Ti}_{5}$. A strategy to circumvent this metallurgical problem, consists in using a precise offset between the joint plane and laser scan plane [1]. Nevertheless, the maximum average UTS for several samples manufactured with similar conditions is around $170 \mathrm{MPa}$ [1] in case of direct laser welding. Another efficient method for avoiding cold cracking induced by these phases due to thermal strains is to modify the chemistry of the melted zones by introducing an insert material compatible with titanium and stainless steel at once. Among compatible materials, vanadium is certainly the best choice for applications in which biocompatibility is not concerned [2]. Finally, analysis of available literature $[3-5]$ shows that embrittlement of this dissimilar combination can be efficiently avoided by applying two pass joining, where the vanadium insert is

\footnotetext{
* e-mail: rodolphe.bolot@ubfc.fr
}

first welded with titanium alloy and then with stainless steel. A brittle $\sigma$ phase $(\mathrm{FeV})$ exists in the $\mathrm{Fe}-\mathrm{V}$ system, but it has a low kinetic of formation, and can therefore be avoided in laser welding.

For this, laser welding in keyhole mode provides deep and narrow seams. However, thermal strains in dissimilar seams remain high due to quenching of the welds occurring during cooling from the solidus down to the ambient temperature. This thermal strain gives rise to high stresses in the seam and its vicinity. Despite that, the tensile strength of assemblies manufactured with a vanadium insert may remain high with UTS as high as $500 \mathrm{MPa}$ [6], especially in the absence of metallurgical problems such as formation of brittle phases. The problematics of residual stresses is thus of high concern, because of the existing mismatch in thermophysical properties, and contraction of the melted material during cooling after solidification. Undesirable stresses and deformations are even more pronounced in case of joining of thin sheets in butt configuration [7]. In the last five years, finite element modeling of the thermomechanical behavior during fusion dissimilar welding has been actively developed [7-9]. It involves sequential calculation of the heat flow problem (using equivalent source approach), and the mechanical one (initiation and accumulation of strains and stresses) 
Table 1. Experimental conditions used to manufacture $\mathrm{Ti} / \mathrm{V}$ and $\mathrm{V} / \mathrm{SS}$ welds.

\begin{tabular}{lll}
\hline & Ti6Al4V/vanadium & Vanadium/316L \\
\hline Lineïc energy $(\mathrm{J} / \mathrm{mm})$ & 6.8 & 10 \\
Spot size $(\mu \mathrm{m})$ & 100 & 100 \\
Beam offset from joint plane $(\mu \mathrm{m})$ & 0 & $50(316 \mathrm{~L}$ side) \\
\hline
\end{tabular}

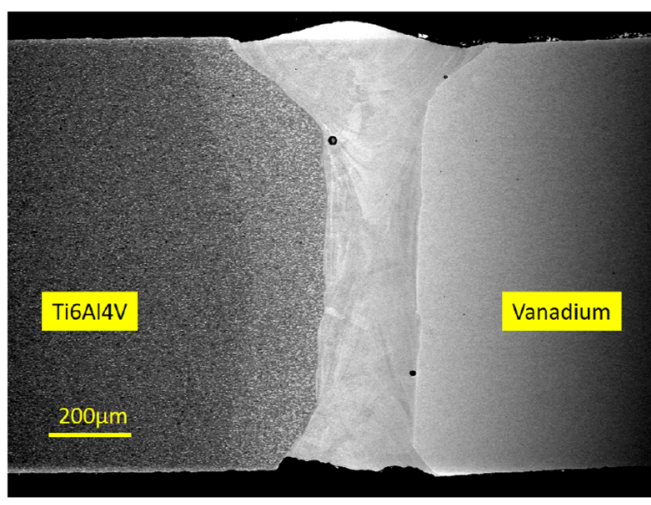

(a)

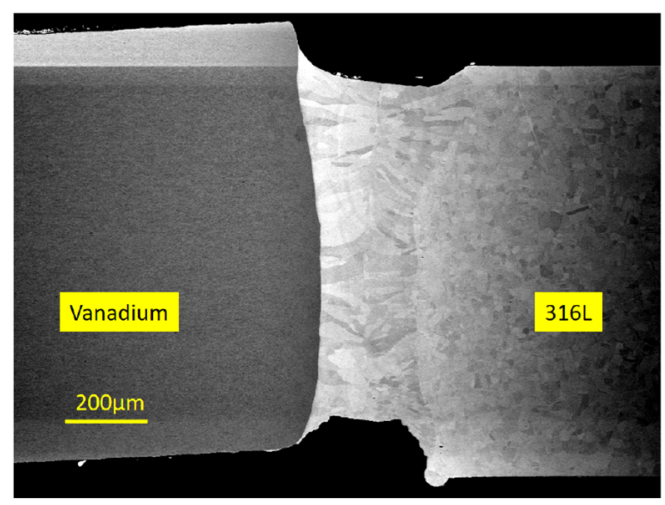

(b)

Fig. 1. Ti6Al4V/vanadium weld (a), vanadium/SS316L weld (b).

during and after the welding operation. Two distinct models were thus developed in the frame of the present work, in order to deepen our understanding of phenomena involved in the welding process and bonding mechanisms. The first one is a 3D large-scale model (typical resolution of $100 \mu \mathrm{m}$ ) aiming to study the thermomechanical behavior of the assembly during the transient welding process. Results obtained with this first model were presented in $[10,11]$. The second one is based on a microscale approach (typical resolution of $3 \mu \mathrm{m}$ ) and is more detailed in the present work: the capacities of this second model are thus illustrated hereafter.

\section{Experimental results}

The case of welding of one-millimeter thick plane sheets with a two-millimeter wide vanadium insert was considered. A continuous wave Yb:YAG Laser, Trumpf Trudisk $6001^{\circledR}$, was used to manufacture the welds, with moderate laser power range, and a $100 \mu \mathrm{m}$ beam spot diameter providing narrow welds. The assembly was manufactured in two steps: the first one consisted in manufacturing a weld between Ti6Al4V alloy and vanadium, and the second one a weld between vanadium and 316L stainless steel. Table 1 summarizes experimental conditions for these two weld seams.

Figure 1 shows cross-sections of the two weld seams. Figure 1a (left) shows the macrostructure of the Ti6Al4/ vanadium weld seam. In this picture, the titanium alloy at left hand side clearly shows a Heat Affected Zone (HAZ) with a width of about $200 \mu \mathrm{m}$. The width of the weld is about $235 \mu \mathrm{m}$ (middle), $650 \mu \mathrm{m}$ (top), and $390 \mu \mathrm{m}$ (bottom).
Due to the differences in the melting temperature of materials $\left(1910^{\circ} \mathrm{C}\right.$ for vanadium, against $1650{ }^{\circ} \mathrm{C}$ for Ti6Al4V), and low laser light absorption, the chemical composition of the seam was found to be slightly staggered in the titanium side (i.e., average $\mathrm{V}$ content of about 33 at $\%$ in the weld despite the absence of beam offset for this weld). Figure 1b (right) shows the macrostructure of the vanadium $/ 316 \mathrm{~L}$ weld seam. The width of this seam is about $240 \mu \mathrm{m}$ (middle), $425 \mu \mathrm{m}$ (top), and $320 \mu \mathrm{m}$ (bottom). Due to the staggering between the laser scan plane and joint plane (i.e., beam offset of $50 \mu \mathrm{m}$ on the $316 \mathrm{~L}$ side as indicated in Tab. 2), the chemical composition of the weld is closer to that of stainless steel (i.e., average vanadium content of about 11 at\% only in the seam). The height of this second weld is about $840 \mu \mathrm{m}$ only, which may contribute to lower the bonding strength. Despite that, experiments showed that rupture does not take place in the seams. More details about the corresponding experimental results (i.e., EDS analyzes, $\mathrm{XRD}$, EBSD, tensile strength) are provided in $[6,12]$. In particular, maximum UTS of $500 \mathrm{MPa}$ was reached for parameters given in Table $1[6,12]$. In addition, more details concerning results computed with the $3 \mathrm{D}$ transient large-scale model were reported in $[10,11]$.

Figure 2 shows a macrograph of the assembly after tensile test up to rupture. Rupture takes place in the vanadium insert close to the vanadium $/ 316 \mathrm{~L}$ seam at about $500 \mathrm{MPa}[6,12]$. Burrs are present along the bottom edge of sheets, due to cutting of the tensile specimens in a larger welded sheets. A deformation of initially horizontal cutting stripes is clearly observed in the vanadium insert, giving rise to a decrease of the section where the rupture takes place. 
Table 2. Mechanical properties obtained from NHT measurements.

\begin{tabular}{llllll}
\hline & Ti6Al4V & Weld Ti side & $\mathrm{V}$ & Weld 316L side & $316 \mathrm{~L}$ \\
\hline $\mathrm{H}_{\mathrm{IT}}{ }^{*}(\mathrm{GPa})$ & $3.8(0.14)$ & $3.5(0.06)$ & $1.7(0.04)$ & $3.4(0.15)$ & $2.1(0.06)$ \\
$\mathrm{HV}_{\mathrm{IT}}$ & 354 & 333 & 163 & 325 & 201 \\
$\mathrm{E}(\mathrm{GPa})$ & $126(3)$ & $102(3)$ & $128(2)$ & $192(5)$ & $172(7)$ \\
\hline
\end{tabular}

* Corresponding $\mathrm{HV}$ values were derived as $\mathrm{HV}_{\mathrm{IT}}=0.0945 \mathrm{H}_{\mathrm{IT}}$ for a Vickers indentor.

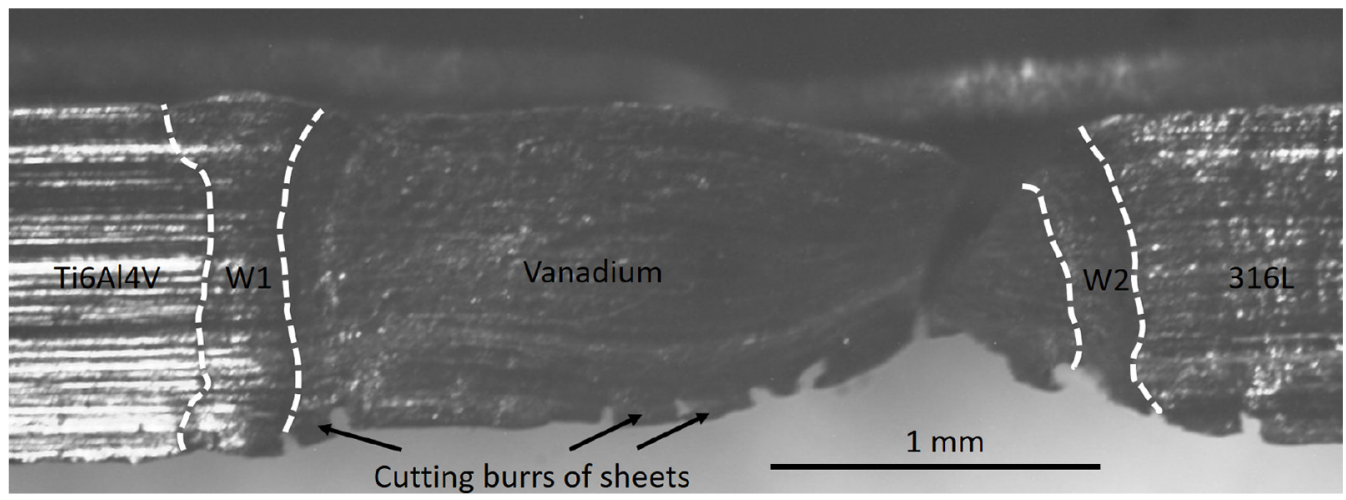

Fig. 2. Example of macrograph of the assembly after tensile test.

\section{Numerical model}

Microscale FEM approach may be used to estimate effective properties of porous or multicomponent materials, according to methods described for example in [13]. In the present work, calculations were conducted directly on the micrograph of the two-pass assembly in order to investigate residual stresses linked to thermal strains in the welds. The computed results illustrate the abilities of this microscale FE modeling approach, which uses directly cross-sectional micrographs of the assembly as mesh, by applying an in-house conversion program. The steps are thus the following ones:

- Forming an image of the assembly cross-section in which the different materials are clearly identifiable.

- Applying thresholds and other image treatments to provide a 6 -color image for the 6 distinct materials (i.e., titanium alloy, stainless steel alloy, vanadium, $\mathrm{Ti} / \mathrm{V}$ weld seam, SS316L/V second seam, +voids around the assembly).

- Converting this image into an APDL script using our inhouse program: each pixel of the image is hence converted into a square element with assignment of the material ID depending on the pixel color: this step allows forming an ANSYS mesh with 6 distinct materials.

- Applying a suitable thermal strain to elements of the seams to provide the residual stress field after the twostep welding operation: for this step, the corresponding load has to be ramped (i.e., progressive increase) to allow convergence of calculations.

- Simulating any type of loading, such as a tensile test for example.
Figure 3 shows the 6 -color image corresponding to the above two-pass assembly. This image was generated by applying thresholds and other image processing methods. The resolution is $3.1 \mu \mathrm{m} /$ pixel and the picture dimensions are $377 \times 1175$, giving rise about 443000 pixels and the same number of square elements in the FE model.

\section{Materials properties}

Estimations of local mechanical properties were obtained from Nano-Hardness Testing (NHT) measurements performed by Anton-Paar France (Courtaboeuf), and considering the Oliver-Pharr method. In details, three different NHT filiations of 120 points were performed across the assembly (from the left side to right side and at three distinct heights in Fig. 3).

Table 2 summarizes NHT results. The associated uncertainties corresponds to statistical dispersions considering a confidence level of $95 \%$ (i.e., each value in between brackets corresponds to $2 \sigma / \sqrt{n}$, in which $\sigma$ stands for standard deviation, and $\mathrm{n}$ is the number of measurements). Results obtained for the Young's modulus are fully consistent with data reported in the literature for Vanadium (i.e., $128 \mathrm{GPa}$ ). However, the measured Young's modulus is somewhat low for $316 \mathrm{~L}$ (172 GPa for NHT measurements against $196 \mathrm{GPa}$ according to the literature, i.e., $-12 \%$ ) and somewhat high for Ti6Al4V (126 GPa against $111 \mathrm{GPa}$, i.e., $+14 \%)$. Finally, the Young's modulus of the Ti6Al4V/vanadium weld is weakened regarding to that of the $\mathrm{Ti}$ alloy and pure vanadium. On contrary, the Young's modulus of the $316 \mathrm{~L} / \mathrm{V}$ weld is higher than that of Vanadium and stainless steel. In 


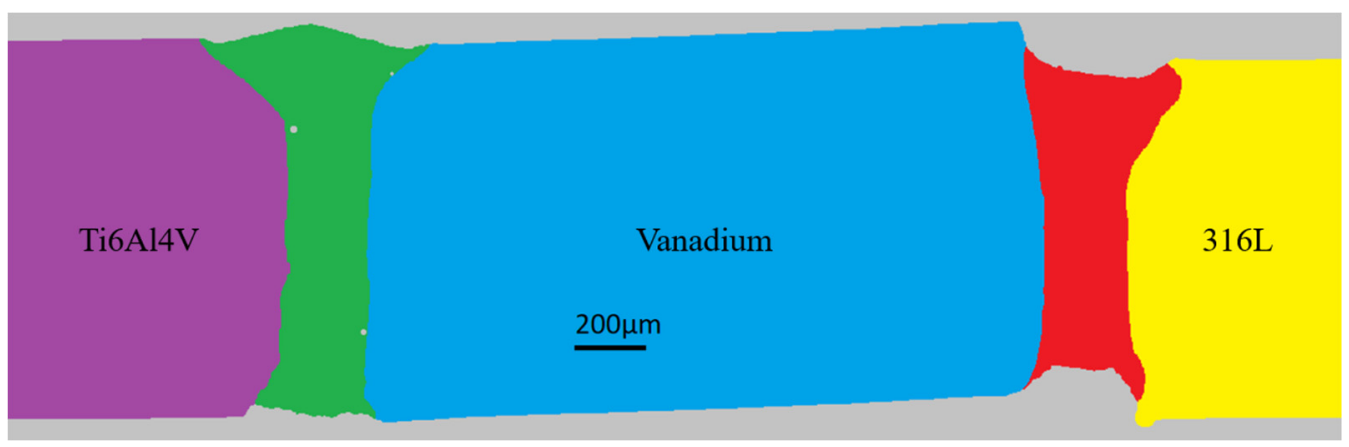

Fig. 3. View of the 2D mesh used in the second model (2-D stationary thermomechanical model with about 4,43,000 elements).

Table 3. Yield strength derived from indentation tests with a spherical tip (weld seams and vanadium) and from the literature (316L steel and Ti6Al4V).

\begin{tabular}{llllll}
\hline & Ti6Al4V & Weld Ti side & V & Weld 316L side & $316 \mathrm{~L}$ \\
\hline$Y_{S}(\mathrm{MPa})$ & 1000 & $404(19)$ & $252(15)$ & $434(19)$ & 320 \\
$E_{T}(\mathrm{GPa})$ & 1.5 & 1.4 & 1.3 & 2.7 & 2.5 \\
$E_{T} E(\%)$ & 1.2 & 1.4 & 1.0 & 1.4 & 1.4 \\
$\nu$ & 0.34 & 0.34 & 0.365 & 0.3 & 0.3 \\
\hline
\end{tabular}

practice, this result is related to the hardening effect of 316L steel with the increase of the Vanadium content in the weld, due to phase separation observable at the nanoscale only. According to the concerned results, hardness values are increased from $200 \mathrm{HV}$ to $500 \mathrm{HV}$, when the Vanadium content is increased from almost 0 to $50 \%$. For the present case, the Vanadium content is about $10 \%$ due to the beam offset on the 316L side, as mentioned in Table 1 . The hardening effect is thus moderate.

Complementary indentation measurements were performed in order to estimate the Yield strength, above which a plastic behavior is reached. These measurements were also performed by Anton-Paar by using a spherical tip indentor. This geometry allows delaying entrance in the plastic domain, in comparison with a Berkovich tip indentor. In theory, it is thus possible to estimate an equivalent stress-strain curve. In practice, a spheroconical tip with radius of $50 \mu \mathrm{m}$ was used for these measurements. Table 3 summarizes the Yield strength results measured with this method for the two welds and for Vanadium. For stainless steel and Ti6Al4V alloy, data taken from the literature were used [14-17]. In addition, data used to setup bilinear constitutive laws were also added in this table. For this, the ratio between the tangent modulus and Young's modulus was assumed to be about $1.4 \%$ for most materials. This value is quite similar to that retained in $[14,15,18]$ for $316 \mathrm{~L}$ stainless steel. For Ti6Al4V, the retained value of $1.5 \mathrm{GPa}$ for the tangent modulus, provides a stress increase of about $300 \mathrm{MPa}$ in the plastic domain for a plastic deformation of $20 \%$ which seems realistic according to data of [17]. However, in all cases, the high Yield strength considered for Ti6Al4V gives rise to a pure elastic behavior of this material for all conditions considered in this study, meaning that the tangent modulus of Ti6 Al4V is in fact not meaningful for next computations (the Yield strength of Ti6 $\mathrm{Al} 4 \mathrm{~V}$ is never reached in following calculations).

Figure 4 illustrates the mechanical properties of materials applied in the present model. Bilinear stress/ strain constitutive laws were considered. For this, the vanadium material shows the lowest Yield strength, whereas that of Ti6Al4V is the highest.

In view of the lack of properties concerning expansion coefficients of the welds materials, they were considered as follows:

- Ti6Al4V/vanadium seam: thermal expansion coefficient of Ti6Al4V and reference temperature corresponding to the melting temperature of Ti6Al4V alloy.

- 316L/vanadium seam: thermal expansion coefficient of $316 \mathrm{~L}$ and reference temperature corresponding to the melting temperature of 316L stainless steel.

In other words, the reference temperature of Ti6 Al4V and $316 \mathrm{~L}$ sheets was assumed to be equal to the ambient temperature and the same for the vanadium insert also. However, the reference temperature of the material of the Ti6Al4V/vanadium seam (green color in Fig. 3) was set to $1650{ }^{\circ} \mathrm{C}$, and that of the $316 \mathrm{~L} /$ vanadium seam (red color in Fig. 3) was set to $1400^{\circ} \mathrm{C}$. from:

By doing so, the thermal strain $\varepsilon_{T}$ is thus computed

$$
\varepsilon_{T}=\int_{T_{r e f}}^{T} \alpha d T=\bar{\alpha}\left(T-T_{r e f}\right)
$$




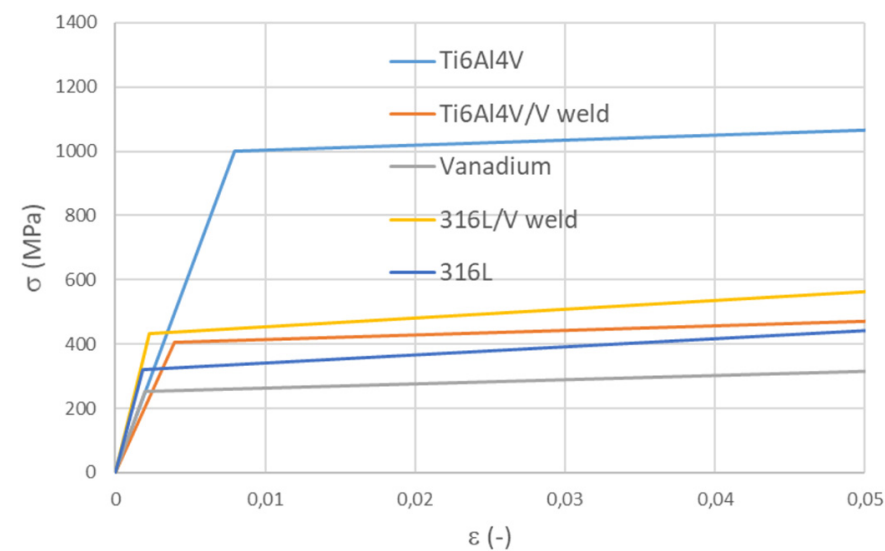

Fig. 4. Bilinear stress/strain constitutive laws applied for the base materials and the two welds.

This method takes into account the materials quenching during cooling from the melting temperature to the ambient one. Concerning the expansion coefficients, either the instantaneous (namely $\alpha$ ) or average (namely $\bar{\alpha}$ ) coefficient can be provided. Within ANSYS, the instantaneous coefficient is stored in variable named CTEX whereas the average one is named ALPX. It is important to highlight that $\alpha$ does not depend on the reference temperature $T_{\text {ref }}$ (but that $\bar{\alpha}$ does).

In this example, six different materials are thus considered: from the left to the right Ti6Al4V (1, purple), first weld (2, green) including a few small pores, vanadium insert (3, blue), second weld $(4$, red) and stainless steel (5, yellow) (Fig. 3). The last material stands for the grey color around the assembly: the corresponding material has low properties (i.e., such as a Young's modulus of $0.1 \mathrm{MPa}$ for example), or the corresponding elements may alternatively be killed, as done in the present work.

\section{Numerical results}

Figure 5 illustrates the resulting thermal strain in the welded assembly after cooling down to ambient temperature. Since $T=T_{r e f}=T_{a m b}$ in the base materials, the corresponding thermal strain is zero (i.e., red color in Fig. 5). On the contrary, $T_{\text {ref }}$ corresponds to the solidus temperature in the seams and a shrinking $\left(\varepsilon_{T}=-2.835 \%\right.$ for the $316 \mathrm{~L} /$ vanadium weld) occurs during cooling down to the ambient temperature. Despite the higher melting temperature of Ti6Al4V, the integral of equation (1) is the highest for $316 \mathrm{~L}$ stainless steel, according to our data. The main assumption of the present model is thus that unmelted parts of the assembly deform only slightly during the welding operations. In practice, during laser welding with these type of conditions, heating is very localized around melted areas. Moreover, the sheets are massive in comparison with the welds, so that the parts of the sheets that are heated by conduction are localized (small heat affected area). In addition, heated parts present low mechanical properties, due to the decrease of mechanical properties such as the Young's modulus with temperature

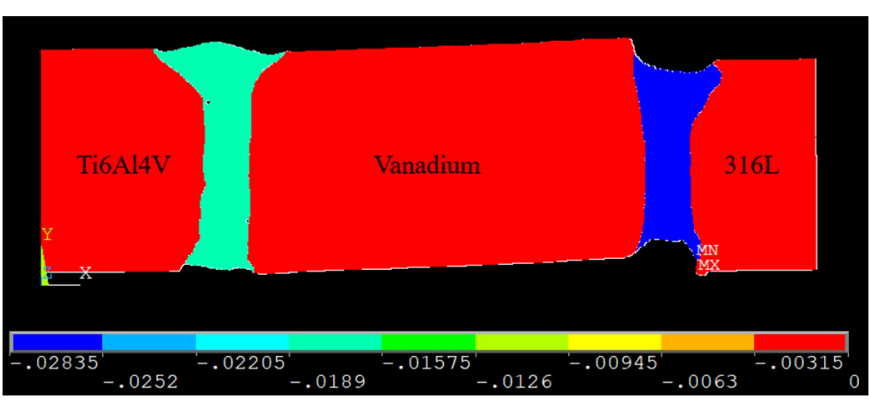

Fig. 5. Field of thermal strain (dimensionless) in the whole assembly.

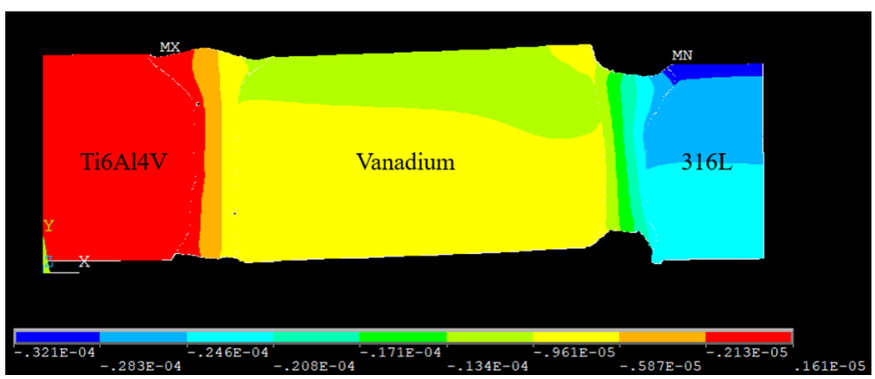

Fig. 6. Displacement field $U x(\mathrm{~m}), X$ being the horizontal direction.

as shown for example in [14]. For these reasons, heated areas have low strength in comparison with the stiff sheets, so that deformations of areas close to the weld remain small. This assumption may easily be validated by comparisons with a full 3D transient model approach at much lower resolution. In all cases, the thermal strain is always calculated according to equation (1) even for a 3D transient model, so that corresponding Figures after overall cooling, look very similar in comparison with Figure 5 (i.e., only three remaining distinct colors after cooling down to room temperature).

Figures 6 and 7 present the computed displacement fields in the $X$ and $Y$ directions, these directions being respectively the horizontal and vertical ones in Figure 3. The $U x$ displacement is zero at the left bottom side (i.e., boundary condition) and remains almost zero everywhere in the Ti6Al4V material. Due to the $X$ shrinking of the $\mathrm{Ti} / \mathrm{V}$ seam, the $U x$ value is negative and quite homogeneous in the vanadium insert. Due to the $X$ shrinking of the $\mathrm{V} / 316 \mathrm{~L}$ weld, the $U x$ value is in the blue color (i.e., negative) in the $316 \mathrm{~L}$ material (right side). In addition, the shrinking is slightly higher at the top than at the bottom (i.e., the width of the weld is higher at the top so that the corresponding shrinking is higher). The $U y$ component is zero at the left/bottom point (i.e., boundary condition). The $U y$ value is low everywhere in the assembly, except in the welds, that show a negative $U y$ displacement at the top side, and a positive one (displacement in the direction of the top) at the bottom side. These displacements are wholly explained by the vertical contraction of the welds (i.e., $Y$ shrinking). In conclusion, these two figures show easily understandable results, which were expected. 


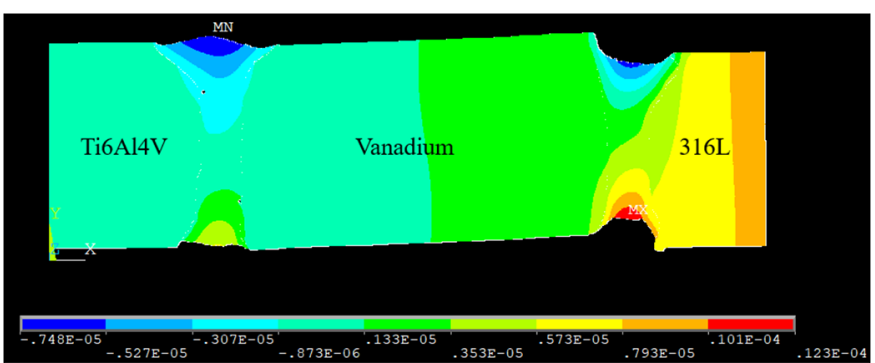

Fig. 7. Displacement field $U y(\mathrm{~m}), Y$ being the vertical direction.

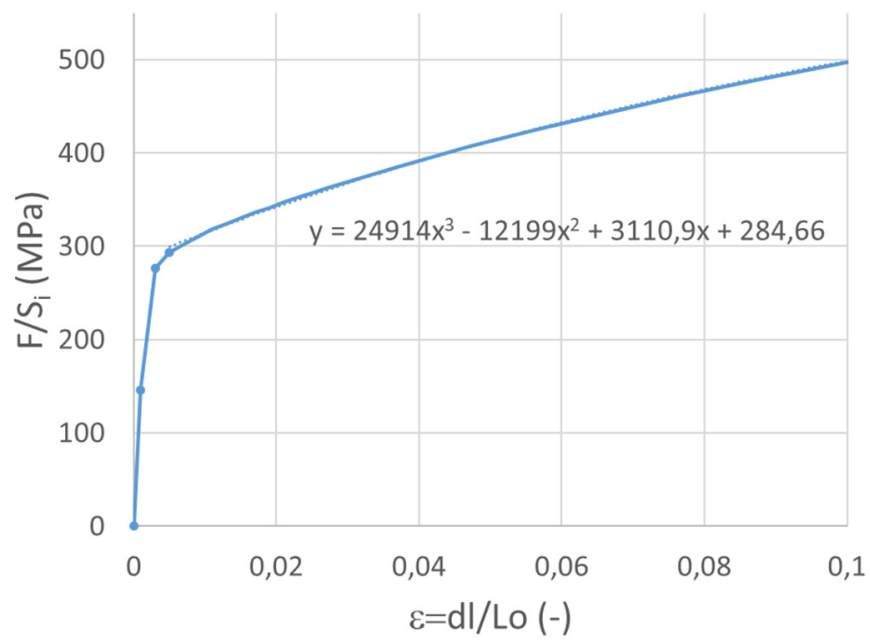

Fig. 8. Stress/strain curve of the area shown in Figure 3.

Figure 8 shows the stress/strain curve deduced from load increase (ramped progressively by steps of $0.2 \%$ for $\left.d l / L_{0}\right)$ on the image of the assembly shown in Figure 3. The stress (vertical axis) is based on the applied load $\mathrm{F}$ and initial section $S_{i}$. For this zone of the assembly, vanadium represents almost $50 \%$ of the total length. The curve shows an elastic part while the load remains lower than the lowest yield strength among the different materials. Once the Yield strength of vanadium is reached, a change in the slope is observed. In a second step, while the load increases, the yield strength of the different materials is progressively reached (except for the titanium alloy that remains in the elastic domain according to the considered mechanical properties) so that the effective slope tends to decrease progressively. In the plastic part, a good fit of data was obtained with a polynomial interpolation curve. From $500 \mathrm{MPa}$, a perfect plastic constitutive law should be used for vanadium to account for the decrease of the loading force during rupture due to the decrease of the cross-section. However, deformation of elements becomes too high to consider this part of the curve. Experimentally, the decrease of the sample section during rupture occurs close to the $316 \mathrm{~L} /$ vanadium weld as shown in Figure 2, which is either related to the presence of stronger stresses or a slight softening of the vanadium in the heat affected zone (HAZ) close to the weld, which was confirmed by slightly higher mark sizes during indentation with the spherical tip indentor used to estimate the yield strength.

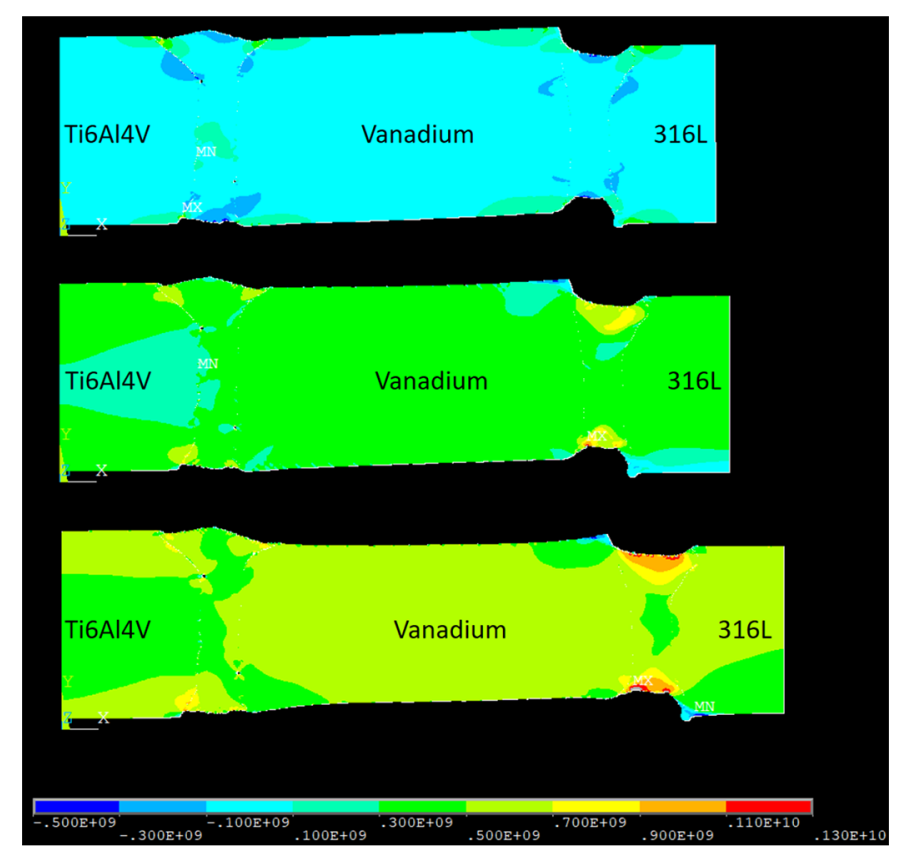

Fig. 9. Comparison of the $\sigma_{X}$ stress component $(\mathrm{Pa})$ after welding operation (top) and during application of a tensile load in the $\mathrm{X}$ direction (347 MPa: mid-height; $500 \mathrm{MPa}$ : bottom).

Figure 9 shows a comparison of $\sigma_{X}$ component of stresses for three different states. The top image corresponds to the residual stress state after welding and cooling (i.e., without any load). In the middle, results are shown for an intermediate tensile load of $347 \mathrm{MPa}$. At the bottom, the case of a load of $500 \mathrm{MPa}$ (experimental value of the UTS) is considered. In order to allow a suitable comparison between the different conditions, the color scale was adjusted in common for the three pictures. As expected, the $\sigma_{x}$ component increases during tensile load. In details, the $\sigma_{x}$ component is mostly in the range $-100 \mathrm{MPa}+100 \mathrm{MPa}$ before tensile load (top figure), in the range $+300 \mathrm{MPa}$ $+500 \mathrm{MPa}$ (central green level) in most areas, after application of the tensile load of $347 \mathrm{MPa}$, and in the range $+300 \mathrm{MPa}+700 \mathrm{MPa}$ (second green color level) for the bottom figure corresponding to the experimental value of the UTS. Finally, the highest magnitude of $\sigma_{x}$ is found in the top and bottom of the $316 \mathrm{~L} /$ Vanadium weld column, where the height of the assembly is the lowest (i.e., lowest cross-section), which implies a high mechanical strength of this weld bead.

Figure 10 shows a comparison of the $\sigma_{y}$ stress component, $\mathrm{Y}$ being the vertical direction (i.e., that of the thickness), for the residual stress state after welding operation (top), and the stress states for tensile loads of $347 \mathrm{MPa}$ and $500 \mathrm{MPa}$ respectively. Again, the color scale was set in common for the three images. The $\sigma_{y}$ component is quite low in most of areas (green color level: $-50 \mathrm{MPa}$ $+100 \mathrm{MPa}$ ). A tensile stress state is observed in the two welds after the welding operation (top): this result is related to the shrinking of the welds materials during cooling from the solidus temperature to the ambient temperature. Because the thermal strain is higher in the 


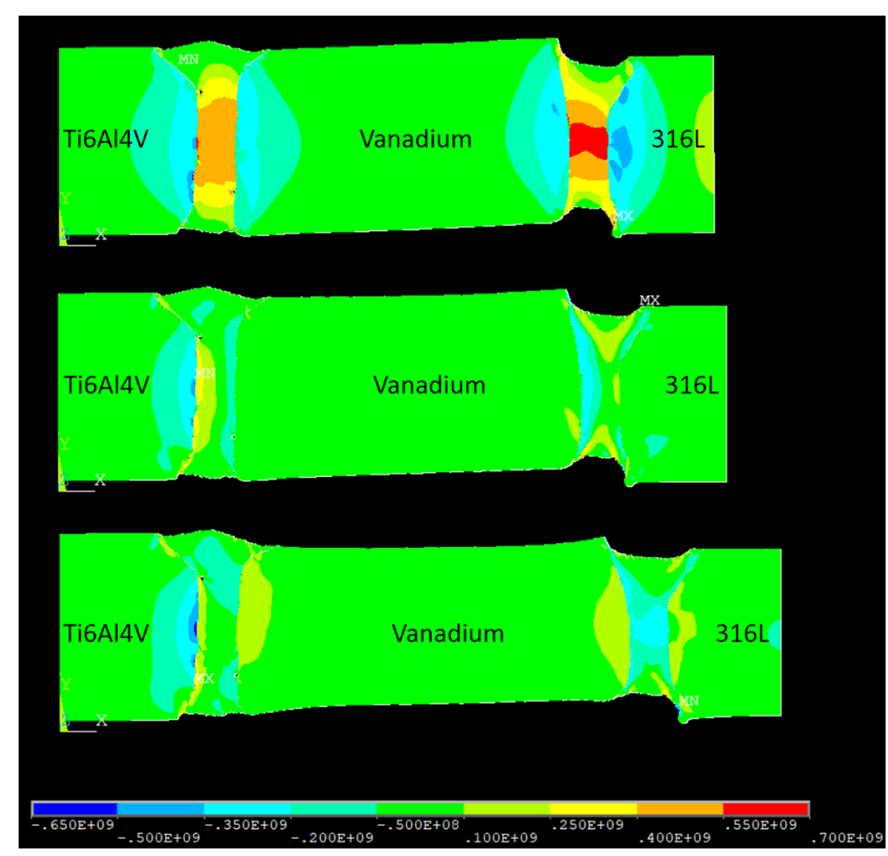

Fig. 10. Comparison of the $\sigma_{y}$ stress component (Pa) after welding operation (top) and during application of a tensile load in the $\mathrm{X}$ direction (347 MPa: mid-height; $500 \mathrm{MPa}$ : bottom).

$316 \mathrm{~L} /$ vanadium weld as suggested in Figure 5, the tensile stress is somewhat higher for this weld in comparison with the left one (i.e., Ti6Al4V/vanadium weld). Tensile stresses in the welds are balanced by compressive stresses in regions in vicinity of both welds. The $\sigma_{y}$ component decreases in the two weld seams during tensile loading: tensile loads in the $\mathrm{x}$ direction provide a compression in the $\mathrm{Y}$ direction, giving rise to a decrease of $\sigma_{y}$. It is thus interesting to note that the $\sigma_{y}$ component decreases strongly in the welds during application of the tensile load. In particular, the 316 /vanadium weld is in a compressive stress state after application of a tensile load at $500 \mathrm{MPa}$. The case of the Ti6Al4V/vanadium weld is somewhat more complex: due to the low deformation of the titanium alloy (which remains in the elastic domain), the $\sigma_{y}$ component remains tensile in the weld in vicinity of the Ti6Al4V sheet. This tensile $\sigma_{y}$ component decreases rapidly for increasing distances from the Ti6Al4V interface.

Figure 11 shows the same comparison for the $\sigma_{z}$ component, $Z$ being the direction perpendicular to the cross-section (i.e., the direction of the weld axis). After welding, the $\sigma_{z}$ component is tensile in the two welds and compressive in materials in the vicinity of beads (i.e., dark blue areas). Again, the $\sigma_{z}$ component does not increase in the welds during tensile load in the $X$ direction. Nevertheless, the plane strain assumption applied in the present 2D high-resolution model acts certainly on the results, even if one can assume that the shrinking of the plate is higher in the thickness than in the $\mathrm{Z}$ direction, especially for the case of a long plate in the $\mathrm{Z}$ direction. One may thus expect, that the present simulation is more representative of the case of a long plate (in the $\mathrm{Z}$ transverse direction) than a real

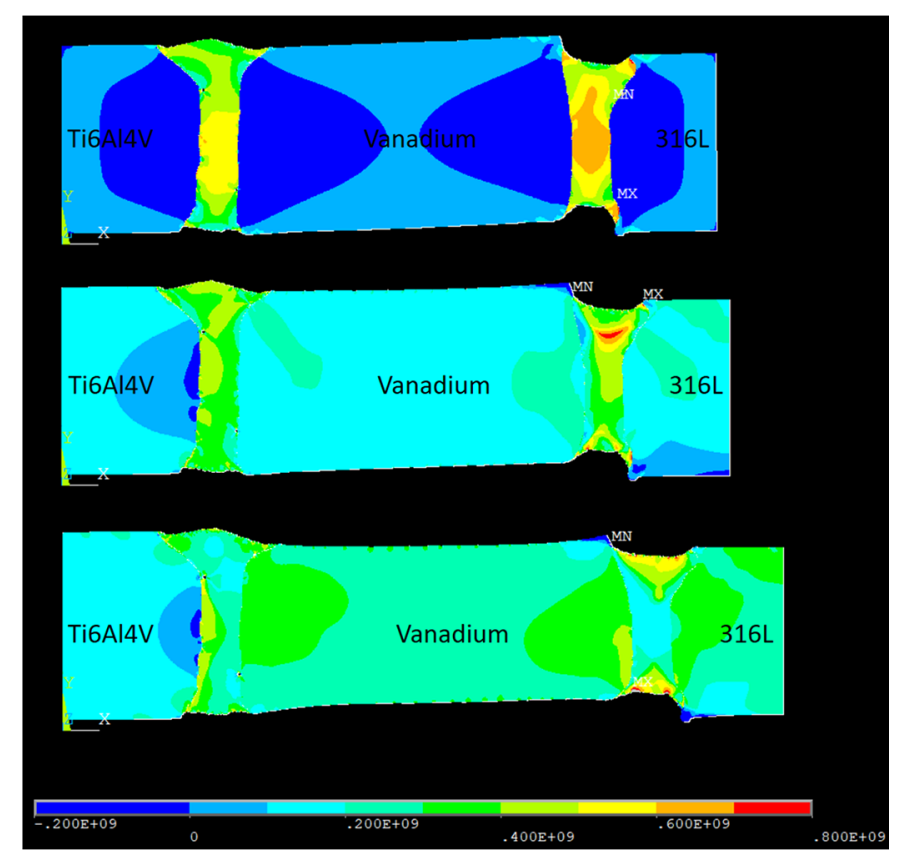

Fig. 11. Comparison of the $\sigma_{z}$ stress component (Pa) after welding operation (top) and during application of a tensile load in the $\mathrm{X}$ direction (347 MPa: mid-height; $500 \mathrm{MPa}$ : bottom).

tensile test specimen. However, comments previously given for the $\sigma_{y}$ component, also prevail for the $\sigma_{z}$ component. In particular, during application of the load, the $\sigma_{z}$ component remains tensile in the Ti6Al4V/vanadium weld near the Ti6Al4V interface, and this tensile component is balanced by a compressive component in the unmelted Ti6Al4V.

Figure 12 shows the resulting Von Mises stress fields for the three same conditions (i.e., residual stresses after the welding operation, and stress fields during application of an increasing tensile load on the assembly). In the initial state (i.e., residual stresses), the equivalent Von Mises stress is high in the welds only due to the shrinking of the welds during their cooling. The Von Mises equivalent stress tends to decrease in the welds during application of the tensile load at $347 \mathrm{MPa}$, whereas it tends to increase in the Ti6Al4V sheet, in the $316 \mathrm{~L}$ sheet and in the vanadium insert. This trend tends to amplify during increase of the tensile load in the X direction. However, the contour of the $316 \mathrm{~L} /$ vanadium weld shows a high stress level, especially at the top and bottom sides of the column, where the $\sigma_{Y}$ stress component in the highest, as suggested by Figure 9 . Nevertheless, the Yield strength and stiffness is higher for the $316 \mathrm{~L} /$ vanadium weld in comparison with corresponding data for the vanadium insert (see Tabs. 2 and 3 and Fig. 4). Finally, this behavior explains why ductile fracture occurs in the vanadium insert during the tensile load [6,12], in the absence of brittle phases, such as in the present case: vanadium shows the lowest UTS in comparison with Ti6AlV and 316L. In addition, the UTS of welds is also higher than that of vanadium, according to their higher Yield strength as shown in Table 3. According to results of Figure 12 at the bottom, in the vanadium insert, the 


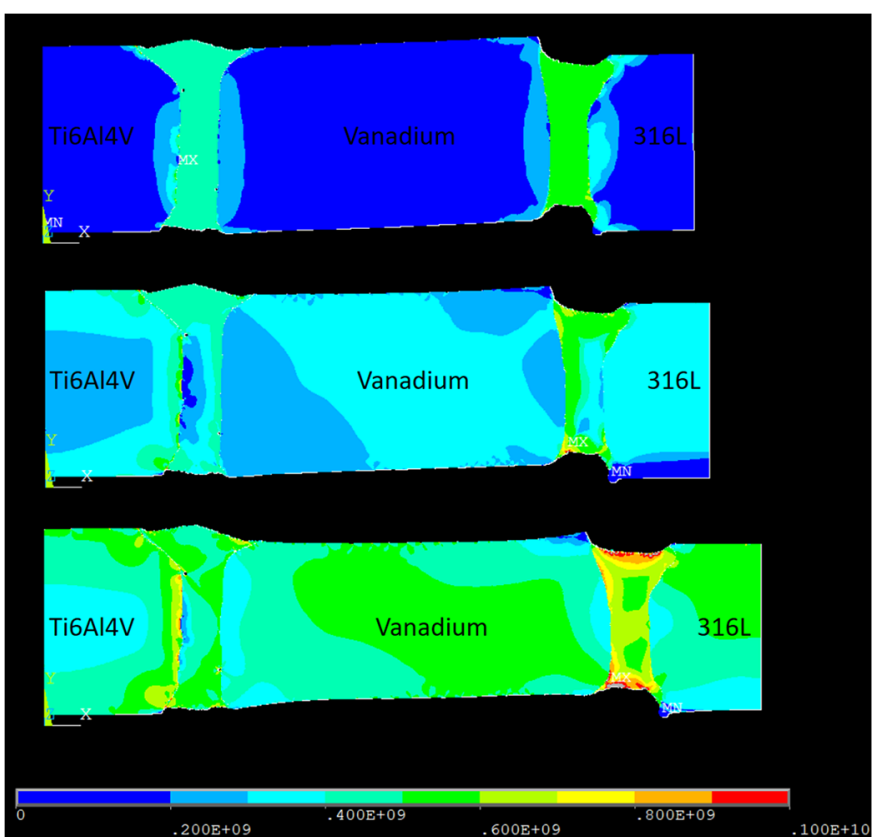

Fig. 12. Comparison of the Von Mises stress ( $\mathrm{Pa}$ ) after welding operation (top) and during application of a tensile load in the $\mathrm{X}$ direction (347 MPa: mid-height; $500 \mathrm{MPa}$ : bottom).

Von Mises stress is lower in vicinity of the $316 \mathrm{~L} /$ vanadium weld. In fact, in the vanadium insert, the Von Mises stress increases while the distance from the vanadium $/ 316 \mathrm{~L}$ interface increases, up to a distance of at least $200 \mu \mathrm{m}$.

Figure 13 shows the evolution of $\sigma_{x}$ and $\sigma_{y}$ stress components along a horizontal line located at the midheight of the assembly. Two distinguishable colours were used for $\sigma_{x}$ and $\sigma_{y}$, and two line-styles were used to distinguish the initial residual stress state (solid line) from the stress states during application of a tensile load $(500 \mathrm{MPa})$. Due to the shrinking of the welds during their cooling, the $\sigma_{y}$ stress component is initially tensile in both welds and compressive in vicinity of welds on both sides. It is clearly seen that the $\sigma_{y}$ stress components tends to decrease in the seams during application of a tensile load along $\mathrm{X}$ direction: this comment would also apply for the $\sigma_{z}$ component, even if, as discussed previously, the decrease is more pronounced for the through-thickness component (namely $\sigma_{y}$ ) due to the plane strain assumption applied in the present $2 \mathrm{D}$ model. For the Ti6 Al4V/vanadium seam, the $\sigma_{y}$ component remains tensile during loading, especially in the region of the interface with the Ti6 Al4V sheet, due to the weak deformation of the titanium alloy (high Yield strength). In the vanadium insert, the $\sigma_{y}$ component is compressive in vicinity of the seams before tensile loading, due to the compression provided by the shrinking of the welds during cooling. However, an inversion occurs during the tensile load, so that the $\sigma_{y}$ stress component becomes tensile near the seam interfaces. Concerning the $\sigma_{x}$ stress component, in the vanadium insert, the highest stress level is located at a short distance (i.e., about $150 \mu \mathrm{m}$ ) from 316L side weld. At the other side from this weld, a similar

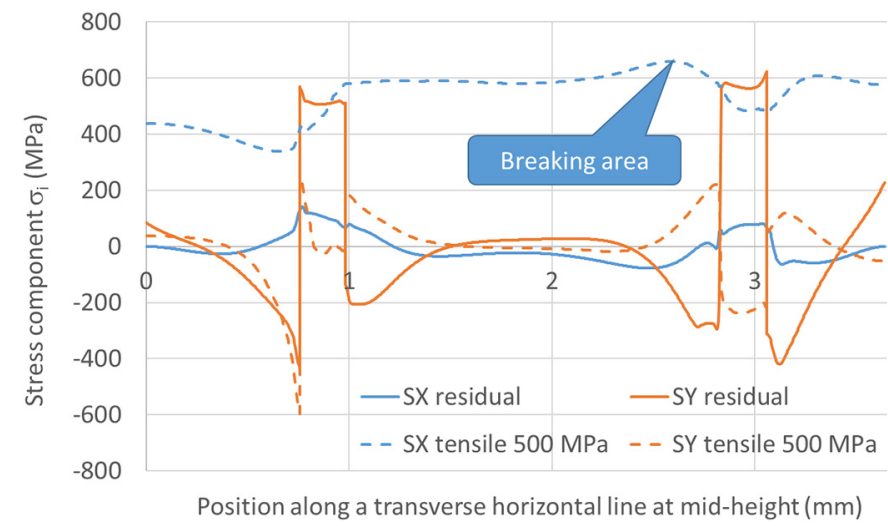

Fig. 13. Evolution of stress components (MPa) along a line located at the mid-height of the assembly.

increase of the stress components is observed in the $316 \mathrm{~L}$ material (Fig. 13 right side dotted blue line). Experimentally, because the UTS of $316 \mathrm{~L}$ is higher than that of vanadium, the ductile fracture occurs in vanadium close to the 316L side weld, as expected from the present results. The model is thus able to predict where the fracture takes place (i.e., in the vanadium insert in vicinity of the $316 \mathrm{~L}$ weld).

\section{Conclusions}

A plane sheet of $316 \mathrm{~L}$ stainless steel was assembled to a plane sheet of titanium alloy (Ti6Al4V) using a $2 \mathrm{~mm}$ wide vanadium insert. Macrographs of the welds were shown and more detailed experimental results were proposed in previous related article [6,12]. This work was thus devoted to show correlated modeling results obtained with a microscale model in which the micrograph of the weld is first assembled, and then used as mesh to perform FEM calculations for the analysis of the residual stresses, as well as evolution of stresses during tensile loading. In this model the mesh is hence the micrograph itself with resolution of about $3 \mu \mathrm{m}$, and six different material areas were considered, namely $316 \mathrm{~L}$ steel, vanadium, Ti6Al4V, the two welds, and the surrounding environment whose corresponding elements were formerly killed. Estimations of residual stresses related to thermal strains were first performed using this model, by considering the shrinking of welds during their cooling down after solidification. For this, the mechanical properties of materials were first estimated from NHT measurements. Stress components and displacement fields were also calculated for the case of a tensile load applied on the assembly. Results were reported for loads of $347 \mathrm{MPa}$ and $500 \mathrm{MPa}$ respectively, this last value corresponding to the measured UTS of the assembly. The results show that $\sigma_{x}$ and $\sigma_{y}$ stress components are tensile in the welds, and decrease during the tensile test due to the $Y$ and $Z$ shrinkage related to the tensile load applied in the $X$ direction. In other words $\sigma_{y}$ and $\sigma_{z}$ stress components tends to decrease during application of the $X$ tensile load. To conclude, the stress 
level in the vanadium insert tends to increase during tensile load in the $X$ direction, while that in the two cords tends to decrease (case of the $\sigma_{y}$ component). Along a horizontal line located at mid-height, the maximum stress level in the vanadium insert is located at about $150 \mu \mathrm{m}$ from the 316L side weld. Experimentally, it is the location where ductile rupture takes place in the vanadium insert during tensile load around $500 \mathrm{MPa}$ for the present condition in absence of brittle phases in the assembly.

\section{Nomenclature}

\author{
$\varepsilon_{T} \quad$ Thermal strain \\ $T_{\text {ref }}$ Reference temperature used to calculate $\varepsilon_{T}$ \\ $\alpha \quad$ Instantaneous dilatation coefficient \\ $\bar{\alpha} \quad$ Average dilatation coefficient \\ $\mathrm{U} \quad$ Displacement component \\ $\sigma \quad$ Stress component \\ $x, y, z$ Subscripts (Cartesian coordinates)
}

Acknowledgements. This work was carried out following joint laboratory project LabCom FLAMme between Laboratoire Interdisciplinaire Carnot de Bourgogne, University of Bourgogne Franche-Comté and SME Laser Rhône-Alpes, funded by French National Agency of Research (grant number ANR-14-LAB3-0005). This work is part of project MPA 2017, supported by Regional Council of Bourgogne Franche-Comté through the Plan d'actions régional pour l'innovation (PARI) and the European Union through the PO FEDER-FSE Bourgogne 2014/2020 programs.

\section{References}

1. A. Mannucci, I. Tomashchuk, A. Mathieu et al., Direct laser welding of pure titanium to austenitic stainless steel, Proc. CIRP 74, 485-490 (2018)

2. I. Tomashchuk, P. Sallamand, Metallurgical strategies for the joining of titanium alloys with steels, Adv. Eng. Mater. 20, 1700764 (2018)

3. N.K. Adomako, J.O. Kim, J.H. Kim, Microstructural evolution and mechanical properties of laser beam welded joints between pure V and 17-4PH stainless steel, Mater. Sci. Eng. A 753, 208-217 (2019)

4. N.K. Adomako, J.O. Kim, S.H. Lee et al., Dissimilar welding between $\mathrm{Ti}-6 \mathrm{Al}-4 \mathrm{~V}$ and $17-4 \mathrm{PH}$ stainless steel using a vanadium interlayer, Mater. Sci. Eng. A 732, 378-397 (2018)
5. I. Tomahchuk, D. Grevey, P. Sallamand, Dissimilar laser welding of AISI 316L stainless steel to Ti6-Al4-6V alloy via pure vanadium interlayer, Mater. Sci. Eng. A 622, 37-45 (2015)

6. A. Mannucci, I. Tomashchuk, A. Mathieu et al., Use of pure vanadium and niobium/copper inserts for laser welding of titanium to stainless steel, J. Adv. Joining Process. 1, 100022 (2020)

7. T. Bajpe, H. Chelladurai, Z. Ansari, Numerical investigation of transient temperature and residual stresses in thin dissimilar aluminium alloy plates, Proc. Manufactur. 5, 558-567 (2016)

8. A.K. Venkata, C.E. Truman, D.J. Smith, Characterising residual stresses in a dissimilar metal electron beam welded plate, Proc. Eng. 130, 973-985 (2015)

9. U. Hartel, A. Ilin, C. Bantel et al., Finite element modeling for the structural analysis of Al-Cu laser beam welding, Phys. Proc. 83, 1404-1414 (2016)

10. A. Mannucci, R. Bolot, A. Mathieu et al., Numerical simulation of residual stresses in laser welding: application to Ti6Al4V/316L steel assembly with vanadium insert, Lasers Manufactur. Conf. 2019, Contribution 194

11. R. Bolot, A. Mannucci, A. Mathieu et al., Simulation numérique du soudage laser: application à l'assemblage Ti6Al4V/316L avec insert vanadium, $28^{\mathrm{e}}$ Congrès français de Thermique, Belfort, 2020

12. A. Mannucci, I. Tomashchuk, A. Mathieu et al., Pure vanadium insert for efficient joining of Ti6Al4V to $316 \mathrm{~L}$ stainless steel with continuous Yb:YAG laser, Lasers in Manufacturing Conference 2019, Contribution 168

13. R. Bolot, D. Aussavy, G. Montavon, Application of FEM to estimate thermo-mechanical properties of plasma sprayed composite coatings, Coatings 7, 91 (2017)

14. T. Tchoumi, F. Peyraut, R. Bolot, Influence of the welding speed on the distortion of thin stainless steelplates Numerical and experimental investigations in the frameworkof the food industry machines, J. Mater. Process. Technol. 229, 21-229 (2016)

15. A. Mousavi, R. Miresmaeili, Experimental and numerical analyses of residual stress distributions in TIG welding process for 304L stainless steel, J. Mater. Process. Technol. 208, 383-394 (2008)

16. G. Lütjering, J.C. Williams, Titanium, 2nd edn. Springer, Berlin, Deutschland, 2007

17. G. Gilles, Experimental study and modeling of the quasistatic mechanical behavior of Ti6Al4V at room temperature, 2015, PhD thesis, Université de Liège

18. B. Brickstad, B.L. Josefson, A parametric study of residual stresses in multi-pass butt-welded stainless steel pipes, Int. J. Pressure Vessels Piping 75, 11-25 (1998)

Cite this article as: Antoine Mannucci, Rodolphe Bolot, Iryna Tomashchuk, Alexandre Mathieu, Eugèn Cicala, Sébastien Lafaye, On the mechanisms involved in the tensile strength of a dissimilar Ti6Al4V/316L laser welded assembly, Metall. Res. Technol. 118, $608(2021)$ 